\title{
Utility Measurement in Integrative Negotiation
}

\author{
Latifa Ghalayini' ${ }^{1}$, Dana Deeb ${ }^{2}$ \\ ${ }^{1}$ Lebanese University, Faculty of Economic Sciences and Business Administration, Lebanon \\ ${ }^{2}$ Lebanese University, Doctoral School of Law, Political, Admin and Economic Sciences, Lebanon \\ lghalayini@hotmail.com, danahdeeb@gmail.com
}

\begin{abstract}
This paper develops an adjustment to utility measurement in integrative negotiation where the negotiation information context is incomplete. The developed function reveals not only win-win outcomes but also deceptive practices where negotiators accept a win-lose deal and then compensate their loss in a deceptive way and greedy practices where negotiators realize their strong competitive position and try to extremely maximize their gains. However, to realize the objective, the utility measurement function literature and theories are reviewed to determine the relevant function structure and the necessary attributes that reveal the desired outcome in an incomplete information context. After examination, relationship measurement is added to the function under two utilities: Decision Utility and Experienced Utility. The foundation of the utility measurement function contributes to revealing satisfying win-win outcomes in an incomplete information negotiation context. Therefore, it develops the negotiation field by designing win-win deals that are beneficial and satisfying in which the advantage is distributed between the negotiators.
\end{abstract}

Keywords: Negotiation, Integrative Negotiation, Utility Measurement, Relationships, Win-win Outcomes.

\section{Introduction}

Negotiation exists in many forms all along with human life. Every human being negotiates at some point in his life, whether at home, at work, at the market, etc. People use negotiation as an interaction tool to realize their needs. Countries use negotiation in external trade and economic strategies and politics. It is "a basic means of getting what you want from others, a back-and-forth communication designed to reach an agreement when you and the other side have some interests that are shared and others that are opposed" (Fisher \& Ury, 1981). It's the process to optimize the individual gain. To maximize gains in negotiation and reach a desired outcome, negotiators follow certain negotiation approaches that assist in building a solution. Distributive negotiation approaches result in win-lose outcomes, in which one negotiator earns at the expense of the other. In short-term deals, this could be profitable and satisfying for the winning party, however, in long-term relationships, these traditional approaches are not desired. On the other hand, integrative negotiation approaches result in win-win outcomes. These approaches use objective criteria, seek designing solutions of mutual gain, and give importance to exchanging information and group problem-solving. Integrative approaches are beneficial for long-term relationships, where both parties are satisfied with the negotiation outcome reached and thus preserve these relationships. Even though distributive strategies could be beneficial in the short term, theoreticians debate on the findings of the negotiation process.

A deal created with a win-lose outcome, or with one party non-satisfied could result in implementation defects. No one pleasure loses. A losing or a non-satisfied negotiator could try to compensate his loss in a way or another, and sometimes in deceptive ways. For example, a contractor signing a deal with an entity having a hard negotiator who designed a deal at the expense of the contractor leaving him unsatisfied could lead this contractor to recover this misplaced deal by lowering quality. Therefore, win-win outcomes and integrative negotiation approach unlike the distributive (win-lose) approach, frame negotiations as a win-win potential, where negotiators create value and distribute gains leaving both sides satisfied. Additionally, win-win outcomes could sometimes be more satisfying for one party than the other. A negotiator with a strong position could exploit his position to extremely maximize his gain at the expense of the other party. Although a win-win outcome is reached, one negotiator earns the biggest portion of the gains' pie leaving the other partially satisfied. Measuring satisfaction and gains entails a utility function that reflects, on one hand, the profitability of an outcome and on the other hand the negotiator's satisfaction with this outcome. However, utility measurement has always been a controversial issue. In multi-attribute negotiations, multi-attribute utility measurement adds additional conflict and complexity. Automating multi-attribute negotiations and utility measurement could serve to deal with part of this complexity. 
Moreover, in integrative negotiations which aim at win-win outcomes, to measure the utility of an outcome, both parties', utilities are to be considered. A win-win outcome should reflect both sides' satisfaction. However, in most negotiation cases, information about the other party is incomplete, where the first party doesn't realize the utility function of the other party. Therefore, the assessment of the utility measurement constitutes an issue in the negotiation process. In other terms, how to assess the utility of an outcome in an incomplete information negotiation context? Could a win-win outcome and negotiators' satisfaction be revealed in this utility function? The objective of this paper is to design a utility measurement function that reflects win-win negotiation outcomes in an incomplete information context. The function reveals not only win-win outcomes but also deceptive practices where negotiators accept a win-lose deal and then compensate their loss in a deceptive way and greedy practices where negotiators realize their strong competitive position and try to extremely maximize their gains. This utility measurement is also helpful in automated negotiations in which measurement is digitized adding more objectivity and transparency to the process. This paper is organized as follows: the second and the third sections cover the methodology in which it overviews the theories behind utility function measurement. Section four demonstrates and details the interrelation between negotiation, relationships and utility measurement. Subsequently, section five describes the adjustment to utility measurement in integrative negotiations. Finally, section six concludes the foundation and contribution of the paper.

\section{Methodology}

To build the utility measurement function, theories form the base to determine the relevant function structure and the necessary attributes that reveal the desired outcome in an incomplete information context. The foundation of such a utility measurement function is a vital step in automated negotiations to assess negotiation offers and reflect whether they are win-win. Theories behind utility measurement function are various. A sort of utility measurement is through the expected value of an outcome using probabilities, while another uses preferences. Measuring utility through its expected value is equal to its payoff times its probability (Bernoulli, 1954 [1738]). While measurement according to expected utility theory (EUT), uses preferences to derive utility (von Neumann \& Morgenstern, 1944). Prospect theory is a further utility measurement theory, which uses probability weightings to describe how people actually make decisions under risk (Kahneman \& Tversky, 1979). Moreover, decision utility theory distinguishes decisions from perception utility under risk rather than how they are perceived (Kontek, 2010). However, utility measurement in a multi-attribute context, like in multi-attribute utility theory (MAUT), assumes that outcome attributes are independent and each has a utility function, which also divides into functions that interrelate linearly or non-linearly (Shaheen, Wooldridge, \& Jennings, 2009). The utility measurement literature is reviewed and the various utility measurement theories are demonstrated to set the relevant measurement function in an incomplete information negotiation context.

\section{Overview of Utility Measurement Function}

Utility in economics is "a measure of satisfaction". It is "the satisfying power of a good or service" (Surbhi, 2016). Economic Utility gives "a relative measure of satisfaction for a product. Based on the requirement of the customer, the product may be assigned its utility. It relies completely on the need and preferences of a customer" (Wall Street Mojo, 2019). Measuring utility has always been arguable. There are two principle theories for utility: cardinal utility and ordinal utility (Surbhi, 2016). The differentiation between cardinal and ordinal numbers was put forward by the German mathematician Ernst Schröder in 1873 (Moscati, 2018). Schröder's cardinal numbers match the unit-based understanding of number and measurement as stated by Aristotle: "cardinal numbers express the total number of units constituting a given quantity, for example, five, and thus are the relevant ones for its measurement. Ordinal numbers, by contrast, come to the fore in the process of counting the units belonging to a quantity and express the position of a specific unit of the quantity, for example, the fifth unit" (Moscati, 2018). Neo-classical economists believed that utility is cardinal, thus can be measured quantitatively like other mathematical variables like weight, height and temperature. They believed that everything could be given a score. As they developed a unit to measure utility known as 'utils'. Thus, 'util' represents "how much psychological satisfaction a product generates for a subset of consumers in many different situations" (Market Business News, 2019). However, modern economists argue that the idea of cardinal utility is unrealistic and they believed that utility is ordinal. 
The utility cannot be measured numerically, but it can be ranked. It is a qualitative measure rather than a quantitative one. It expresses utility in terms of 'less than' or 'more than. Agents (i.e. negotiators) usually have preferences regarding the issues under negotiation, and those preferences guide their behavior. Rational agents aim to maximize their outcomes and choose the ones they most prefer. When preferences are mapped to utility, then the ones with higher utility mean greater preferences but according to Wilkes (2008) two parties' utility values cannot be compared nor can be normalized into a common set. However, von Neumann \& Morgenstern (1944) utility function eventually led economists to elaborate a conception of utility measurement that definitely liberated it from any association with units. It comes from the expected utility hypothesis and states that when a consumer has a list of choices with different probabilities, the optimal choice is the choice that enlarges the expected value of the utility (i.e., satisfaction).

Expected Utility Theory (EUT): Expected Utility Theory emerged with Bernoulli who was the first who argued the expected value of a decision. Then, Von Neumann-Morgenstern used preferences to derive utility instead of using a utility to define preferences as in Bernoulli's model. The following section illustrates EUT according to Bernoulli and Von Neumann-Morgenstern and then demonstrates its formula.

Bernoulli's Formulation: Expected value is among of the first theories of decision-making under risk. The expected value of an outcome "is equal to its payoff times its probability" (McDermott, 1998). This model did not succeed to assume outcomes in many cases because the payoff for an individual is not always only linked to its monetary worth. Bernoulli (1954 [1738]) was the first who noticed the idea and introduced the idea of systematic bias in decision-making based on a "psychophysical" model. Bernoulli explained the constraints of expected value as a decision rule through a coin toss game referred to as the "St. Petersburg paradox". He analyzed that the value that someone links to an outcome can be affected by many conditions as the potential of winning, or probability, among other things and not only linked to the absolute amount of the payoff, or expected value. The subjective value or utility that a payoff has is what explains people's chosen action. People try to increase their utility and not their expected value. Bernoulli proposed a utility function that is not linear, rather it has a concave shape reflecting the notion of decreasing marginal utility i.e. a $\$ 1$ is a lot compared to nothing, whereas $\$ 101$ is not significantly different to most people than $\$ 100$. Bernoulli's model was the start of utility theory.

\section{Figure 1: Bernoulli's Utility Function}

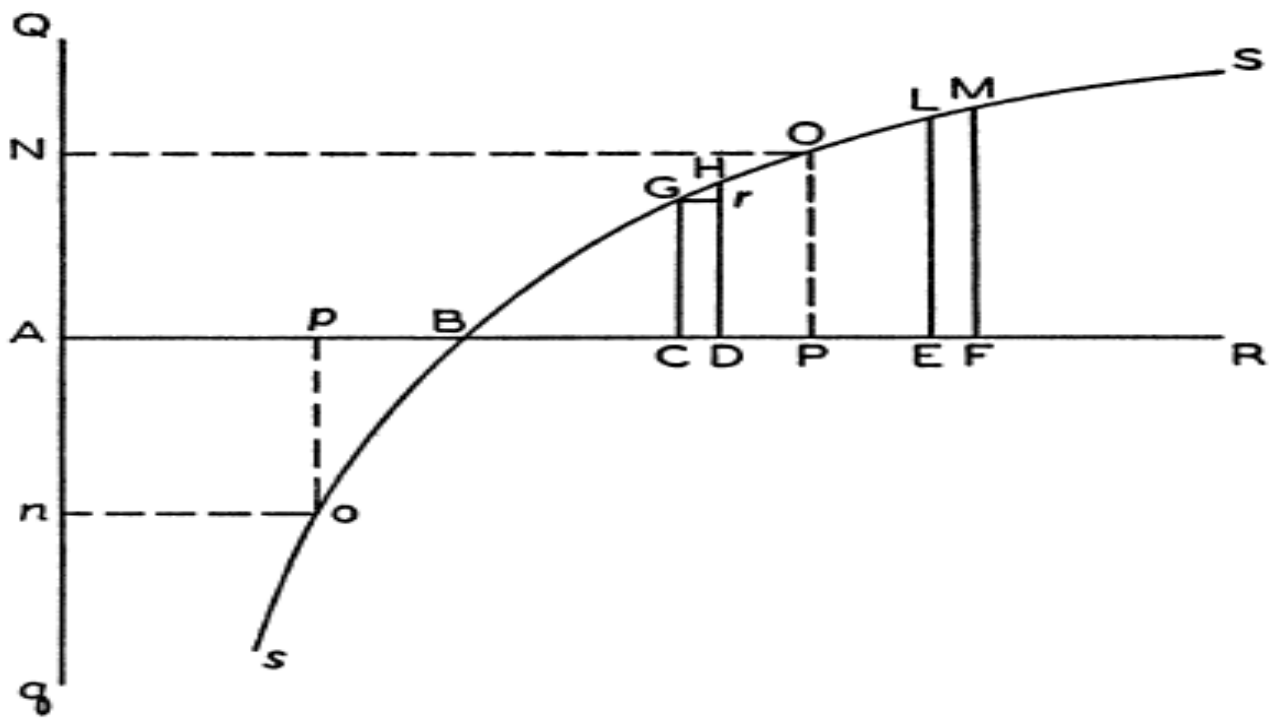

Adapted from "Exposition of a New Theory on the Measurement of Risk (Translation of Bernoulli 1738 Specimen theoriae novae de mensura sortis; Papers Imp. Acad. Sci. St. Petersburg 5 175-192)" by Bernoulli, 1954 [1738], Econometrica, 22(1). Two centuries later, von Neumann and Morgenstern developed Bernoulli's expected utility theory by adding the notion of "revealed preferences" (McDermott, 1998). 
Von Neumann-Morgenstern Formulation: In 1944, John von Neumann and Oskar Morgenstern published their book "Theory of Games and Economic Behavior". They proposed an expected utility function over lotteries, or gambles rather than the utility function over wealth, proposed by Bernoulli. They used preferences to derive utility. In Bernoulli's model utility was employed to define preferences, because it is supposed that people prefer the option that presents the biggest utility. While in von Neumann and Morgenstern model, being aware of the utility of an option gives an idea of a player's preferences, because utility symbolizes the player's preferences (McDermott, 1998). This allowed various individuals to have various preference orderings. In their model, there is no direct differentiation between normative and descriptive aspects. It is stated that the subjective utility value is how individuals usually behave and not how they should behave. To build a utility function, von Neumann and Morgenstern set a number of assumptions with regard to people preferences that are considered as axioms. These assumptions deal with people's rationality and define preference relationships in probabilistic outcomes (Goyal \& Saxena, 2002). They are "(i) completeness, (ii) transitivity, (iii) independence and (iv) continuity" (von Neumann \& Morgenstern, (1953) [1944]).

(i) Completeness means that "people have well-defined preferences and they can decide between alternatives" i.e. they can rank them;

$$
L<M, M<L \text { or } L \sim M
$$

(ii) Transitivity assumes that "preferences are consistent across any three options";

$$
\text { If } L<M \text { and } M<N \text {, then } L<N
$$

(iii)Independence assumes that "a preference holds independently of the possibility of another outcome";

$$
\begin{gathered}
\text { If } L \leq M \text {, then for any } N \text { and } p \in[0,1], \\
p L+(1-p) N \leq p M+(1-p) N
\end{gathered}
$$

(iv) Continuity assumes that "there is a tipping point between being better than and worse than a given middle option";

$$
\begin{aligned}
& \text { If } L<M<N \text {, then there exists a probability } p \in[0,1] \text { such that } \\
& \qquad L+(1-p) N \sim M
\end{aligned}
$$

If all the assumptions are fulfilled, then a player is said to be rational and his preferences can be stated in a utility function. Outcomes' preferences are assigned numbers and choosing the best outcome is through selecting the outcome with the greatest expected utility. Then, a rational individual chooses an alternative over the other only if its expected utility exceeds the other. The expected utility of any decision may be represented as a linear combination of the utilities of the outcomes, with the weights being the respective probabilities. An individual selects not the highest value of an outcome, but rather the highest expected utility.

Expected Utility Formula: When the entity $x$ whose value $x_{i}$ affects a person's utility takes on one of a set of discrete values, the formula for expected utility, which is assumed to be maximized (Kontek, 2010) is:

Equation 1. Expected Utility Formula

$$
E[u(x)]=\sum_{i=1}^{n} u\left(x_{i}\right) p_{i}
$$

Where; the left side is the subjective valuation of the gamble as a whole, $x_{i}$ is the ith possible outcome, $\mathrm{u}\left(\mathrm{x}_{\mathrm{i}}\right)$ is its valuation, and $p_{i}$ is its probability. Adapted from "Theory of Games and Economic Behavior (Third ed.)" by von Neumann \& Morgenstern (1953) [1944]), Princeton University Press.

Confidence and Skepticism to EUT: According to (Moscati, 2018), EUT measurement history is split into a notion of confidence in EUT and EUT-based measurement of utility, and another notion of skepticism to the model and its theory. In the 1950s, a number of researchers showed trust in EUT-based measurement, while from the mid-1970s other researchers doubted its validity. Among the researchers believing in EUT, are three groups of scholars who conducted research at Harvard and Stanford: statistician Frederick Mosteller and psychologist Philip Nogee (1951), philosophers Donald Davidson and Suppes with the collaboration of psychologist Sidney Siegel (1957), and Suppes and his student Karol Valpreda Walsh (1957). They aimed to validate the theory by neutralizing some psychological factors. Their findings were in line with both the 
experimental measurability of utility based on EUT and the descriptive validity of the theory. In line with these findings, another two studies were conducted at Yale in the 1960s.

One by economist Trenery Dolbear (1963), and the other by psychologist Gordon Becker and statistician Morris DeGroot in association with Marschak (1964) also supported EUT and showed its validity in decision making. However, between the late 1960s and the early 1970s, a group of young psychologists at the University of Michigan: Sarah Lichtenstein, Paul Slovic, and Tversky argued the validity of EUT. And their work began to be called "Behavioral Economics" in the late 1980s. Moreover, and in contrast to Mosteller, Suppes, and the other experimenters of the 1950s and 1960s who used psychological factors to validate EUT, Karmarkar (1974), McCord and Neufville (1983), and Hershey, Kunreuther and Schoemaker (1982) used such factors to falsify it. They found that different elicitation methods to measure utility, which according to EUT should come up with the same outcome, in fact, generate different measures. They undermined the earlier confidence about EUT. Moscati (2018) concludes that "such findings contributed to destabilizing EUT.

As the dominant economic model of decision-making under risk and helped foster the blossoming of non-EUT models that began in the mid-1970s and has continued to the present". Additionally, applying expected utility to decision-making entails being aware of the probabilities of various outcomes. But practically probabilities might be unknown in many situations. Thus, probabilities are assumed and then the expected values become sensitive to such assumptions. Another point to consider when using EUT is the incomparability between agents. EUT does not give any canonical way to distinguish two utility functions. Hence expressions like $u_{x}(L)+u_{y}(L)$ and $u_{x}(L)-u_{y}(L)$ are not canonically defined, nor are comparisons like $u_{x}(L)<u_{y}(L)$ canonically true or false. In particular, "total VNM-utility" and "average VNM-utility" of a population are not canonically meaningful without normalization assumptions. So, despite the truth that all of the assumptions of von Neumann and Morgenstern seem logically correct, people do violate them in actual choice behavior. This is one of Tversky and Kahneman's crucial findings (McDermott, 1998) of Prospect Theory (PT).

Prospect Theory: Tversky and Kahneman (1979) argued that the majority of people disobey most of the assumptions of subjective expected utility theory. They empirically presented a critique to the theory through controlled experiments and developed an alternative model, called prospect theory. It is a descriptive theory of choice, where it describes how people actually make decisions. It states that people are more risk-averse in the domain of gain and risk seekers in the domains of losses. Like Bernoulli's proposition, prospect theory is based on psychophysical models. Psychophysics studies the correlation between the "physical" and the "psychological worlds"; usually mathematically expressed. The aim is "to determine the point at which a change in the physical stimulus is psychologically perceived as a sensory change by the subject" (McDermott, 1998). Tversky and Kahneman used psychophysical principles to study "judgment" and "decision-making". For example, when the brain translates vision into sight, people do not know how the brain engages. The same applies to decision-making when editing and evaluating choices, people do not know the computations the brain does. Thus, people make a decision according to how their brain processes information and not only to the utility a certain option possesses for them. Prospect theory describes the decision process in two stages: "(i) editing or framing phase and (ii) evaluation phase".

(i) The Editing phase is meant to serve as a preliminary analysis of a prospect. It specifies rules on how to simplify a problem. People split outcomes by setting a reference point and then regarding lesser outcomes as losses and greater ones as gains. It attempts to reduce the framing effects and resolve the isolation ones. This model changes the whole cumulative distribution function instead of transforming each probability separately, as it separates gains from losses and preserves most of the essential features of the prospect theory. Framing effects "refer to the way in which a choice, or an option, can be affected by the order or manner in which it is presented to a decision-maker" (McDermott, 1998). And isolation effects stem from individuals' tendency to often remove consecutive probabilities instead of treating them together. "When multiple stimuli are presented, the stimulus that differs from the rest is more likely to be remembered" (von Restorff, 1933).

(ii) In the Evaluation phase, people choose among the options the alternative with the highest utility. This is influenced by the subjective value and the perceptual likelihood of an outcome. Prospects theory has common features with prior principles of expected utility. Like Bernoulli, it assumes that 
the value functions of all individuals have the same shape of the curve. And like von Neumann and Morgenstern, it considers that the curve is not a straight line and the utility of the curve might vary between individuals (McDermott, 1998).

Figure 2: The Value Function Assumed by PT and Figure 31: A Typical Weighting Function for PT CPT (concave for gains, convex for losses)
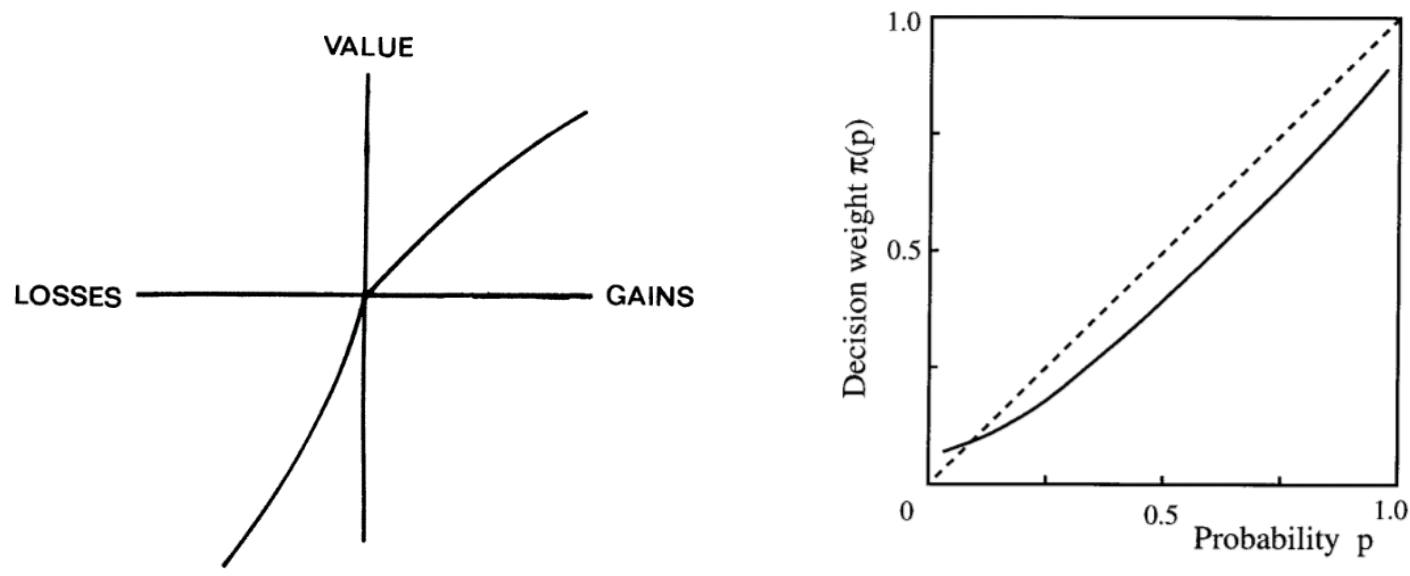

Figure 2 and Figure 3 are adapted from "Prospect Theory: An Analysis of Decision under Risk" by Kahneman and Tversky (1979), Econometrica.

Because all individuals have the same value curves' shape, it is not necessary to be aware of a person's specific utility in every scenario. Whenever the domain is clear, assumptions become possible regardless of the particular individuals' utilities. It predicts according to a distinction between a decision that occurs in the domain of gains or in the domain of losses (McDermott, 1998). Tversky and Kahneman (1992) developed a new sort of prospect theory that uses cumulative rather than separable decision weights and develops the theory in different dimensions. This version is called Cumulative Prospect Theory (CPT). It permits different weighting functions for gains and for losses, as it is used to any number of outcomes.

Figure 4: A Typical CPT Weighting Function

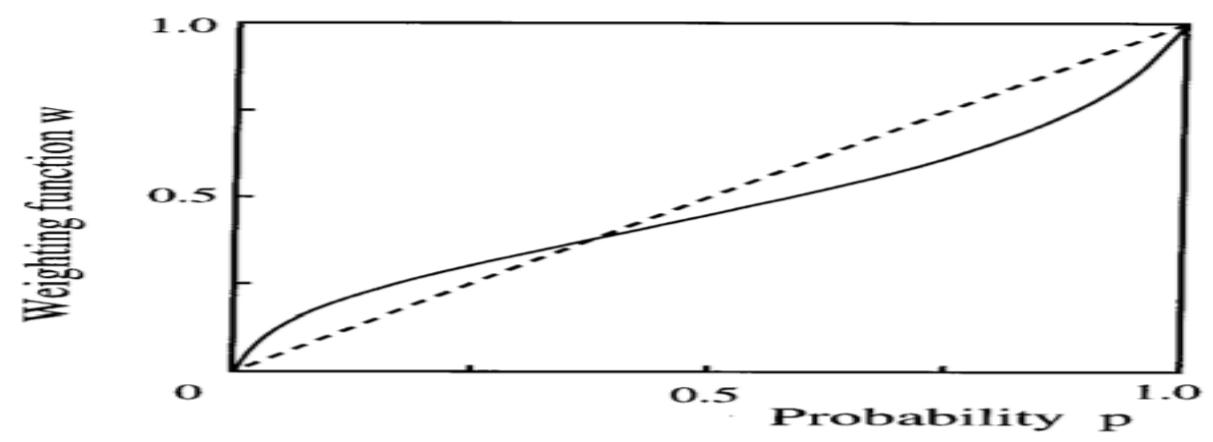

Adapted from "Advances in Prospect Theory: Cumulative Representation of Uncertainty" by Tversky and Kahneman (1992), Journal of Risk and Uncertainty. In the classical theory, the utility of an uncertain prospect "is the sum of the utilities of the outcomes, each weighted by its probability" (Kahneman \& Tversky, 1979). Tversky \& Kahneman suggested two important alterations of this theory: "(i) the carriers of value are gains and losses, not final assets; and (ii) the value of each outcome is multiplied by a decision weight, not by an additive probability". The weighting scheme adopted in the prime version of prospect theory and in other models is a monotonic change of outcome probabilities (Tversky \& Kahneman, 1992). This scheme faces two 
issues. First, it does not always fulfill stochastic dominance ${ }^{1}$, which several theorists refuse to neglect. And second, it is not easily expanded to a large number of outcomes.

Tversky and Kahneman (1992) proposed solving these issues by applying the rank-dependent or cumulative functional, first suggested by Quiggin (1982) for decision under risk and by Schmeidler (1989) for decision under, uncertainty. Results from their experiments assert a distinctive fourfold pattern of risk attitudes: "risk aversion for gains and risk-seeking for losses of high probability; risk seeking for gains and risk aversion for losses of low probability".

Decision Utility Theory: Prospect Theory (1979) and its Cumulative version (1992) use probability weighting to assess outcomes. Decision Utility Theory provides another solution, which does not use this concept, to solve most of the problems encountered in expected utility theory as argued by Kontek (2010). It "distinguishes decision and perception utility, postulates a double S-shaped decision utility curve similar to one hypothesized by Markowitz (1952), and applies the expected decision utility value similarly to the theory by von Neumann and Morgenstern (1944)" (Kontek, 2010). Decision utility theory describes decisions made under risk rather than stating how individuals perceive outcomes. It compares outcomes by their certainty equivalents instead of the hypothetical "utils" used in EUT and PT, thus allows for cardinal measurement instead of ordering options. Kontek (2010) explains two interesting findings in his experiments. He found that "the utilities are not concave as usually assumed by economists. Instead, they are S-shaped and, interestingly, seem to be similar in all the ranges considered". However, no single utility presents in all the ranges. The decision utility curve shape represents the one hypothesized by Markowitz (1952). It has three inflection points as Markowitz predicted. But it differs in that the decision utility is a function of outcomes expressed in relative rather than absolute terms as suggested by Markowitz. It is almost identical to EUT's formula, but rather expressed in relative terms.

Figure 5: Decision Utility Function $p=D(r)$ for Gains and Losses

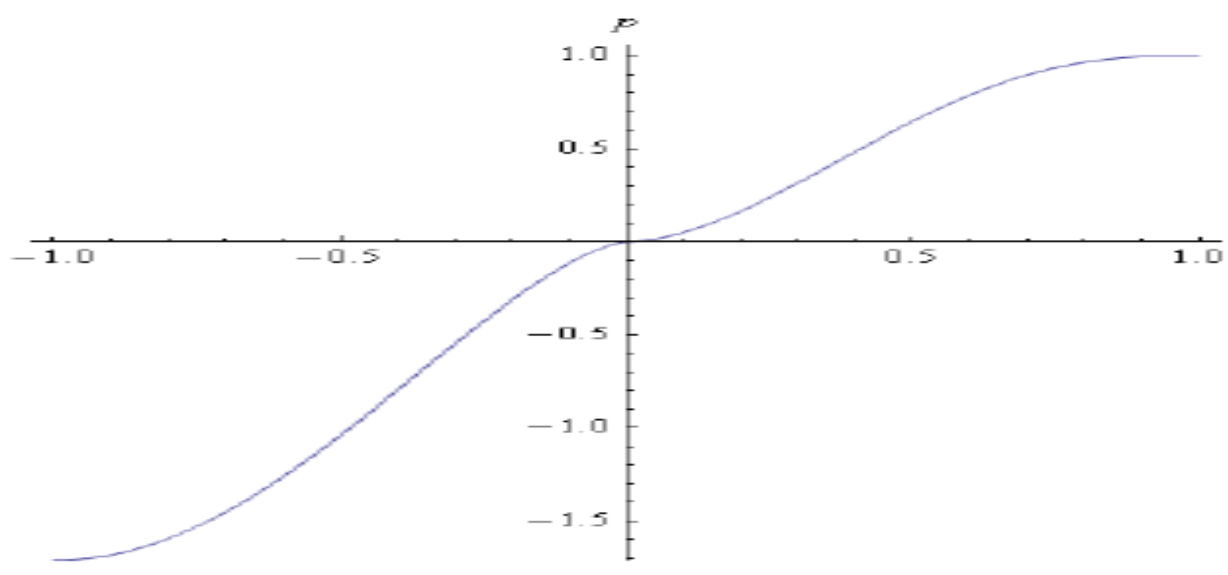

Adapted from "Decision Utility Theory: Back to von Neumann, Morgenstern, and Markowitz" by Kontek, 2010, MPRA: Munich Personal RePEc Archive.

\footnotetext{
${ }^{1}$ Stochastic dominance "is a partial order between random variables. It is a form of stochastic ordering. The concept arises in decision theory and decision analysis in situations where one prospect can be ranked as superior to another prospect for a broad class of decision-makers. It is based on shared preferences regarding sets of possible outcomes and their associated probabilities" (Hadar \& Russell, 1969).
} 
Figure 6: Utility Function as Presented in the Markowitz Hypothesis

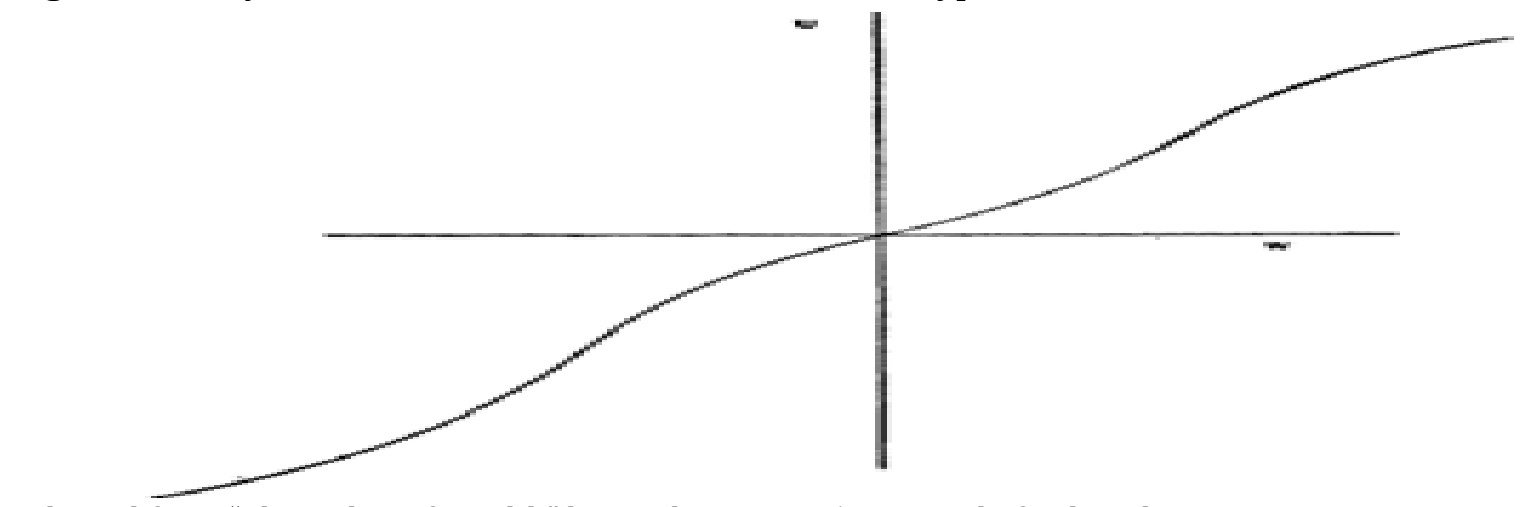

Adapted from "The Utility of Wealth" by Markowitz, 1952, Journal of Political Economy, 60

Markowitz's assumption of expressing the utility function absolutely i.e. in monetary terms has impeded it from explaining the paradoxes observed in experiments and drove to the enhancement of prospect theory (Kontek, 2010). Moreover, and even though experiments from cumulative prospect theory confirmed the distinctive "fourfold pattern of risk attitudes", Kontek (2010) argues that decision utility theory offers a simpler explanation to this pattern. One relates to the double S-shape of the decision utility curve and another relates to the idea of aspiration level i.e. "people take risks until prospective gains are lower than their aspiration levels; people will avoid risks until prospective gains exceed their aspiration levels". This interpretation is not modern and is referred to in Simon's theory of bounded rationality (Simon, 1982). This idea interprets why people initiate new businesses, enter the stock market and alter their partners. It also interprets why people get rid of businesses, buy bonds and stop searching for a new job. Additionally, decision utility theory eliminates stochastic dominance violations, as the way a lottery has resembled does not affect its equivalent probability.

Thus, decision utility theory offers a very different model from Prospect Theory and its cumulative version and returned back to Expected Utility Theory. It eliminated the editing phase, probability weighting, cumulative probability representation and outcome ranking. It doesn't consider the behavioral paradoxes as paradoxical when deviating from the rationality axioms set by EUT but rather describes them as irrationality illusions. Prospect theory and Cumulative Prospect Theory with their descriptive nature and Decision Utility Theory which was originated to describe decisions made, including behavioral paradoxes, all push us to use von Neumann-Morgenstern's Expected Utility Theory as a model to measure outcome utility. The assumption behind EUT regarding "not only the way rational people should behave but do behave" seems relevant to a decision support system trying to explore a win-win collaborative outcome. EUT's rational axioms should reflect negotiators' preferences and resemble their rationality that would be bounded through direct contact. Negotiation automation with a robust rational decision model i.e. EUT model would serve as a promising tool to reach win-win satisfying solutions.

Back to EUT: Enormous theoretical efforts have been devoted to developing alternatives to EUT. Some of these theoretical developments include: regret theory (Loomes \& Sugden, 1987), weighted utility theory (Chew \& MacCrimmon, 1979), the theory of disappointment (Bell, 1982), quadratic utility theory (Chew, Larry, \& Segal, 1991), prospect theory (Kahneman \& Tversky, 1979) and cumulative prospect theory (Tversky \& Kahneman, 1992), rank-dependent expected utility theory (Quiggin, 1981), prospective reference theory (Viscusi, 1989) etc. However, "the field of applications was relatively underdeveloped" as stated by Mark J. Machina $^{2}$ in a roundtable discussion in a conference on the establishment of utility and risk ${ }^{3}$ in 1994 (Starmer, 2000). Additionally, Robert Sugden ${ }^{4}$ also suggested in the same roundtable that a basic theoretical problem needs to be fixed before we claim to have a general descriptive model of choice. He argues that

\footnotetext{
${ }^{2}$ Mark Joseph Machina is an American economist noted for work in non-standard decision theory.

${ }^{3}$ FUR VII, Oslo

${ }^{4}$ Robert Sugden, FBA is an English author in the area of cognitive and behavioural economics. His research combines game theory with moral and political philosophy.
} 
actual choice behavior is more complex than our models and the conventional theories do not reflect such complexity (Starmer, 2000). Furthermore, Blavatskyy (2013) conducted a study to determine the best theories for analyzing decisions under risk. Among the decision theories studied: maximization of expected value (EV), expected utility theory (EUT), Yaari (1987) dual model, Quiggin (1981) rank-dependent utility (RDU), mean-variance approach (MV) proposed by Blavatskyy (2010), Chew (1983) weighted utility (WU), quadratic utility (QU) theory proposed by Chew et al. (1991), disappointment aversion (DA) theory proposed by Gul (1991), prospective reference (PR) theory proposed by Viscusi (1989). He found that EUT is one of the studies that provide the best goodness of fit.

Multi-attribute Utility Measurement: A utility function might represent a single attribute or multiple attributes. When issues under negotiation are numerous or when negotiating a multi-attribute issue, a utility function becomes more complicated and hard (Wilkes, 2008). The following is a description of multi-attribute utility measurement with its formulation.

Multi-attribute Utility Measurement in Words: Representing a multi-attribute issue in a utility function is a complicated task (Wilkes, 2008). Requesting complete multi-dimensional utility functions from people is not easy, so simpler methods are often utilized (Wilkes, 2008). For example, multi-attribute utility theory (MAUT) assumes that outcome attributes are independent and each has a utility function. The group of utility functions are weighted and then added together. A common form of MAUT in human-to-human communication is to use for each individual a table of utility functions that describe each attribute with weights for summing them and then normalizing the results (e.g., into a $[0,100]$ range). The functions and weights can be given to a trusted third-party mediator, who can utilize this data to come up with an "optimal" operating point that increases the total of the overall utility functions for both parties (Wilkes, 2008). The different attributes that contribute to the utilities, might interrelate linearly or non-linearly. When utility functions are non-linear, the equilibrium strategies may be hard to compute (Shaheen, Wooldridge, \& Jennings, 2009). Shaheen et al. (2009) explored two different solutions. The first is using a package deal procedure (PDP) with linear approximations of the given nonlinear utilities. The second solution is using a simultaneous procedure (SP) where the problems are examined at the time but each alone. Although the two solutions computed equilibrium in a certain time, but Shaheen et al. argued that SP may be better for one of the two agents and also increase the social welfare.

Multi-attribute Utility Measurement in Formula: Among the most popular approaches for multi-attribute decision making are the multi-attribute utility theory and multi-attribute value theory where they consider a set of alternatives that have to be ranked according to a number of criteria that have to be optimized (Dyer, 2005). A decision problem is represented in a matrix format to reflect the multiple attributes contributing to the decision, $A:=\left\{a_{1} \ldots . a_{T}\right\}:$ Set of discrete alternatives or techniques

$F:=\left\{f_{1} \ldots . . f_{K}\right\}:$ Set of criteria relevant for the decision

The decision matrix $D:=\left(x_{t k}\right)$ with $\mathrm{t}=1 \ldots . \mathrm{T}$ and $\mathrm{k}=1 \ldots . \mathrm{K}$ is a $s(T * K)$ matrix whose elements $x_{t k}=f_{k}\left(a_{t}\right)$ indicate the evaluation or value of alternative $a_{t}$, with respect to criterion $f_{k}$ :

$$
D=\left[\begin{array}{ccc}
x_{11} & \ldots & x_{1 K} \\
\ldots & x_{t k} & \ldots \\
x_{T 1} & \ldots & x_{T K}
\end{array}\right]:=\left[\begin{array}{ccc}
f_{1}\left(a_{1}\right) & \ldots & f_{K}\left(a_{1}\right) \\
\ldots & f_{k}\left(a_{t}\right) & \ldots \\
f_{1}\left(a_{T}\right) & \ldots & f_{K}\left(a_{T}\right)
\end{array}\right]
$$

Different methods within the different approaches exist. Simple additive rating (SAR), simple additive weighting (SAW), the analytic hierarchy process (AHP), the analytic network processes (ANP), the outranking approach preference ranking organization method for enrichment evaluations PROMETHEE, and many more. SAR and SAW are among the most frequently used methods (Geldermann \& Schobel, 2011). The difference between SAR, SAW, AHP, and ANP, which all utilize a kind of a value function and the outranking approaches like PROMETHEE, is that within the former group of methods the decision-makers know the utility of the various criteria values and are able to determine their corresponding significance. The outranking approaches were developed as a try to surpass some shortcomings of MAUT/MAVT under the assumption that the decision-makers do not know their preferences (Roy \& Bouyssou, 1993). This paper follows an assumption that the negotiators are fully aware of their preferences and are able to express the weightings of 
the different criteria. The problem that it tries to solve is the exploration of the optimal solution that satisfies both parties. Thus, assuming the awareness of the negotiators, SAW will be used as the multi-attribute decision-making method.

Simple Additive Weighting: SAW is founded on building a value function that resembles goal realization according to each criterion, multiplied by the criterion's specific weight. The decision-maker has to set a one-dimensional value-function $v_{k}\left(f_{k}\left(a_{t}\right)\right)$, that is normalized to the interval [0,1], where each criterion's best score is assigned the utility value $v_{k}=1$, and the worst is assigned $v_{k}=0$,

The functions $v_{k}$ are given according to,

$$
\begin{aligned}
x_{\text {max }, k} & :=\max \left\{f_{k}\left(a_{t}\right)\right\} \\
x_{\min , k} & :=\min \left\{f_{k}\left(a_{t}\right)\right\}
\end{aligned}
$$

Equation 2. The Value Functions in SAW

$$
v_{k}\left(f_{k}\left(a_{t}\right)\right)= \begin{cases}\frac{f_{k}\left(a_{t}\right)-x_{\text {min, }}}{x_{\text {max }, k}-x_{\text {min, }}} & \text { if } f_{k}\left(a_{t}\right) \rightarrow \max \\ x_{\text {max,k }}-f_{k}\left(a_{t}\right) & \text { if } f_{k}\left(a_{t}\right) \rightarrow \min \end{cases}
$$

Summing up the functions across all criteria $\mathrm{k}=1 \ldots . \mathrm{K}$, we obtain

\section{Equation 3. Multi-attribute Utility Function}

$$
v\left(a_{t}\right)=\sum_{k=1}^{K} w_{k} \cdot v_{k}\left(f_{k}\left(a_{t}\right)\right) \text { with } w_{k} \geq 0 \text { and } \sum_{k=1}^{K} w_{k}=1
$$

Where $w_{k}$ are again the weighting factors of the criteria $\mathrm{k}$. The higher the weighted sum of the utility values, the better the alternative. Equations 2 and 3 are adapted from "On the Similarities of Some Multi-Criteria Decision Analysis Methods" by Geldermann and Schobel (2011: 221).

\section{Relationships and Utility Function Measurement}

Utility which is a measure of satisfaction is not only concerned with financial satisfaction. Post negotiation relationships are also an important part of a negotiator's outcome (Brown \& Curhan, 2012) that contributes to satisfaction and success. Relationships are associated with expectations and assumptions that influence the negotiation process, including informational exchange, competitive versus cooperative tactics, concession making, etc. Thus, this association between relationships and the negotiation process obviously affects negotiation outcomes and therefore contributes to higher joint gains. According to Brown \& Curhan (2012) relationships between negotiation, parties may sum into a negotiator's combined utility function in three various ways. Relationships affect negotiators' choices with regard to how much pleasant or rough a relationship is, how much it values in the future and whether a negotiator cares to leave a good impact or not. Brown \& Curhan (2012) classified relationships' impact on negotiators' utility into: (i) decision utility, (ii) experienced utility, and (iii) diagnostic utility.

The Decision Utility Concept: A relationship might affect a negotiator's decision by influencing his preferences for different kinds of outcomes. For example, a negotiator might sacrifice with a short-term gain to preserve a relationship that might be financially rewarding in the long term. This is referred to as decision utility. It can be determined through people's choices.

The Experienced Utility Concept: Second, and contrarily with decision theory that discusses the "wantability" of an outcome, relationships may have intrinsic value, in that they might impact how enjoyable the negotiation experience is other than any financial influence. This refers to as "likeability" and known as experienced utility. It can be grounded on either moment utility or remembered utility. Moment utility can be measured through the immediate subjective experience or physiological indices, and remembered utility is measured through past experience (Kahneman, Wakker, \& Sarin, 1997).

The Diagnostic Utility Concept: Finally, the diagnostic utility where negotiators actions and choices become a reason of satisfaction or dissatisfaction relying on whether they affected a person negatively or positively 
with their choices. According to Brown \& Curhan (2012), negotiators might select actions or prefer relationships that improve their personal recognition. Thus, they might steer their choices in a way that affects their utility.

An Adjustment to Utility Measurement in Integrative Negotiation: Relationships seem to be an important driver of negotiators' behavior; either by influencing preferences for different objective outcomes, or by influencing affective reactions experienced during the negotiation, or by providing the chance for negotiators to improve their sense of self. For instance, a negotiator, might not value long-term relationships as he values a mutually profitable agreement. Or a negotiator might not value credibility if he got a profitable offer, although credibility is an important factor to consider. This paper applies two concepts of relationships' utility. It uses decision utility and experienced utility.

Building the Measurement: To assess utilities in integrative negotiations reflecting win-win outcomes, this paper proposes including relationships' measurement to utility measurement. And this is applied by incorporating two relationship measures, decision utility and experienced utility. Decision utility is used to measure how much the negotiator values the relationship with his opponent. It reflects two types of relationships: short-term and long-term. A negotiator, who aims for a short-term relationship, always chooses an offer in line with his advantage i.e. a profitable one for him. However, a negotiator who aims for a longterm relationship might sacrifice with a short-term gain to preserve a relationship (Brown \& Curhan, 2012). On the other hand, experienced utility is used to measure the negotiator's credibility. It is assessed according to the percentage of deviation between the negotiator's past and present offers. If a negotiator deviates strongly from his past offers, whether increasingly or decreasingly, he loses credibility. Each of the negotiator's offers affects decision utility and experienced utility.

If the negotiator's offer does not strongly deviate from his past offers, then he is considered credible, and his (1) experienced utility increases. However, if his offer strongly deviates increasingly or decreasingly, then he is considered non-credible, and his (2) experienced utility decreases. But despite the considerable deviation, a negotiator might suggest a losing offer or prefer to get little gain in order to preserve a long-term relationship (Brown \& Curhan, 2012). Thus, if the negotiator's offer strongly deviates decreasingly from his past offers, then his (3) decision utility increases, although he loses credibility and his experienced utility decreased. This condition has multiple interpretations. A negotiator might values a long-term relationship more than an instant gain or contrarily he might think of reaching an agreement but thereafter deviating from its conditions to recoup his losses. Moreover, if a negotiator's offer strongly deviates increasingly, then he is not only considered non-credible where his experienced utility decreases, but also selfish aiming for his own gain without considering the other party, then his (4) decision utility decreases. 
Figure 7: Utility Measurement Associated with Relationship Utility

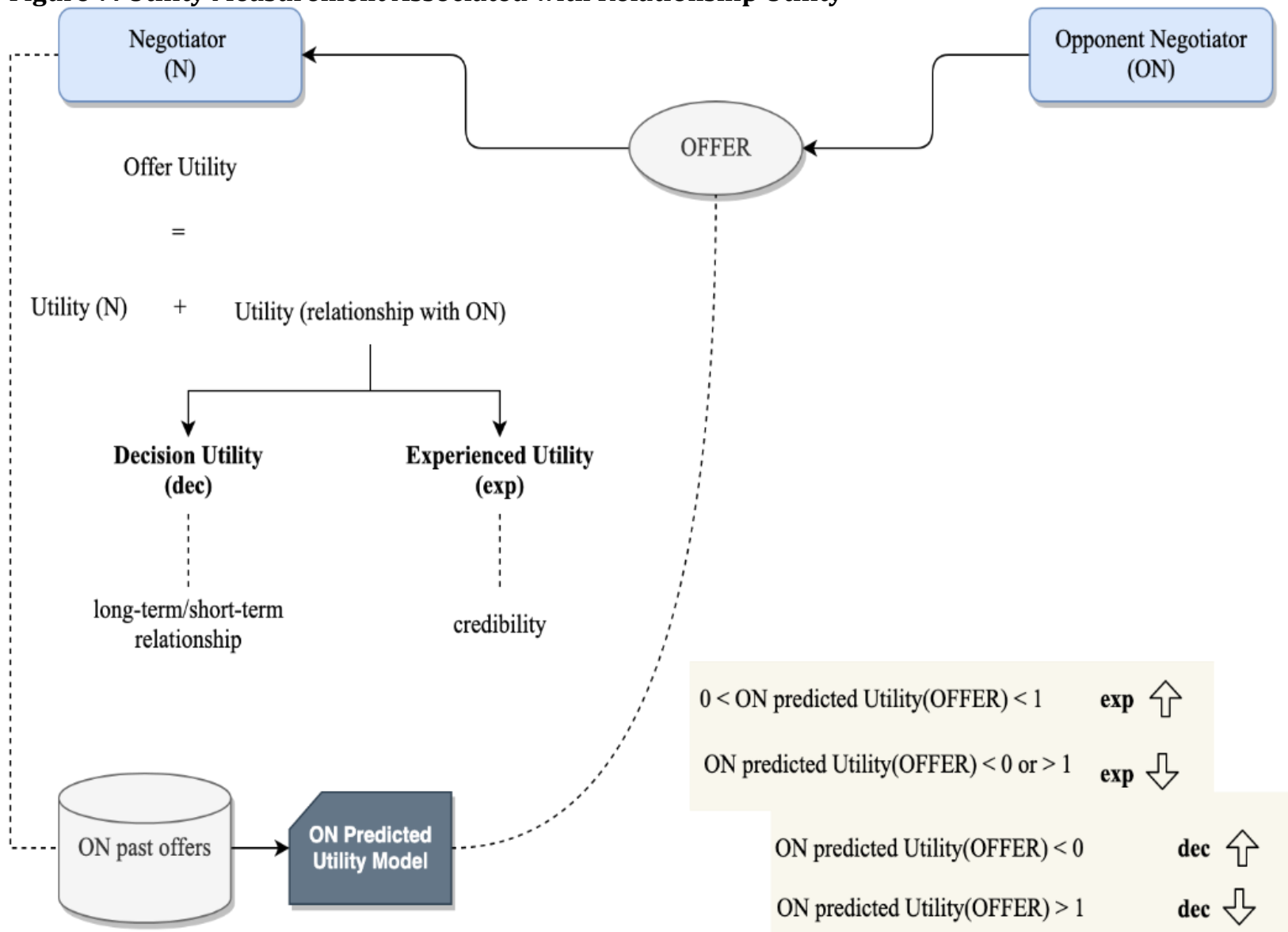

Source: Prepared by the author

Relationship Measurement Formulation: The importance of each of the two utilities that express the relationship's utility, is determined differently according to each negotiator and how much he values his opponent's credibility or short-term and long-term relationships. Thus, each of the two utilities will be associated with a weighting factor that reflects the importance of the specified utility to the negotiator (i.e. $r 1$ and $r 2$ ). Moreover, another weighting factor is added (i.e. $r 3$ ) which reflects the importance level of the relationship to the negotiator. This factor, on one hand, represents how much a negotiator values his opponent's cooperative strategy and on the other hand the importance of coming up with a mutually profitable outcome from both sides and not just for his own advantage. Then, the utility of an offer provided, which is expressed as a one-dimensional value-function $v_{k}\left(f_{k}\left(a_{t}\right)\right)$, when combined with decision utility and experienced utility with their corresponding importance levels, becomes; Equation 4.The Utility Function with Relationship Measurement

$$
\begin{gathered}
v\left(a_{t}\right)=\sum_{k=1}^{K} w_{k} \cdot v_{k}\left(f_{k}\left(a_{t}\right)\right)+r 3(\boldsymbol{r} 1 . \boldsymbol{d e c}+\boldsymbol{r} \mathbf{2} \boldsymbol{e x p}) \\
\text { with } w_{k} \geq 0 \text { and } \sum_{k=1}^{K} w_{k}=1
\end{gathered}
$$

Source: Developed by the author

Where; dec and $r 1$ are decision utility and its importance level respectively, exp and $r 2$ are experienced utility and its importance level respectively, and $r 3$ is the importance level of the relationship with the opponent. This paper aims to design a utility measurement function that helps reach win-win negotiation outcomes. The adjustment lies in reflecting the relationship utility in utility measurement. The two 
relationship utilities: decision utility and experienced utility, are variables to be calculated and added to the utility function. Experience utility is considered an important factor to check the cooperativeness of the other party, where this cooperativeness does not contradict his own advantage. However, decision utility is of lesser importance level since the model developed values designing a mutually beneficial agreement over short-term or long-term relations. Nevertheless, decision utility is important to consider since a negotiator who acts selfishly in a win-win model loses some of his utility and a negotiator who acts altruistically without creating a profitable outcome gains some decision utility but on the other hand, loses more experienced utility.

\section{Conclusion}

Integrative negotiation approaches exceed the restricted strategic options of the distributive approaches (Zartman, 1988), in which in the former, negotiators create value from negotiation to expand their pie of gains. This paper develops an adjustment to utility measurement in integrative negotiations where the negotiation information context is incomplete. The developed function reveals not only win-win outcomes but also deceptive practices where negotiators accept a win-lose deal and then compensate their loss in a deceptive way and greedy practices where negotiators realize their strong competitive position and try to extremely maximize their gains. Therefore, the adjustment of the utility function lies in adding the relationship measure to the utility measurement. It is formed from two utilities: Decision Utility and Experienced Utility. Each of the utilities has a specific weight to adjust the total utility in a way where optimal win-win outcomes are the aim.

Furthermore, the adjustment of the utility measurement contributes to revealing real win-win negotiation outcomes where no deception or greediness exists, gains are distributed and negotiators are mutually satisfied. Negotiating and designing successful deals and contracts that are mutually advantageous requires cooperation, group problem solving and exchanging information as the integrative negotiation approaches entail. Nevertheless, most negotiators don't reveal the necessary information needed to reach such outcomes as in most real-life situations. The adjustment to utility measurement proposed aids to assess negotiation offers in a mutually profitable manner although negotiators conceal information that integrative negotiation approaches seek to disclose. The relationship measure added to the function omits the necessity of revealing information which most negotiators would never do, and aids towards reaching an optimal win-win outcome by considering it as a factor besides profitability in the utility measurement.

\section{References}

Becker, G. M., Degroot, M. H. \& Marscha, J. (1964). Measuring Utility by a Single-response Sequential Method. Journal of the Society for General Systems Research, 9(3), 7.

Bell, D. (1982). Regret in Decision Making under Uncertainty. Operations Res., 20, 961-981.

Bernoulli, D. (1954 [1738]). Exposition of a New Theory on the Measurement of Risk (Translation of Bernoulli D 1738 Specimen theoriae novae de mensura sortis; Papers Imp. Acad. Sci. St. Petersburg 5 175192). Econometrica, 22(1), 23-36.

Blavatskyy, P. (2010). Modifying the Mean-Variance Approach to Avoid Violations of Stochastic Dominance. Management Science, 56(11), 2050-2057.

Blavatskyy, P. R. (2013). Which Decision Theory? Economics Letters, 120(1), 40-44.

Brown, A. D. \& Curhan, J. R. (2012). The Utility of Relationships in Negotiation. Oxford Handbooks Online, 139-151.

Chew, S. H. (1983). A Generalization of the Quasilinear Mean with Applications to the Measurement of Income Inequality and Decision Theory Resolving the Allais Paradox. Econometrica, 51, 1065-1092.

Chew, S. H., Larry, E. G. \& Segal, U. (1991). Mixture Symmetry and Quadratic Utility. Econometrica, 59, 139-63.

Chew, S. \& MacCrimmon, K. (1979). Alpha-nu Choice Theory: a Generalisation of Expected Utility Theory. working paper 669, U. British Columbia.

Chew, S., Larry, E. G. \& Uzi, S. (1991). Mixture Symmetry and Quadratic Utility. Econometrica, 59, 139-163.

Davidson, D. \& Suppes, P. (1957). Decision Making: An Experimental Approach. Stanford University Press, 121. 
Dyer, J. (2005). MAUT - Multi-Attribute Utility Theory. In Multiple Criteria Decision Analysis: State of the Art Surveys. Springer: New York, 265-295.

Fisher, R. \& Ury, W. (1981). Getting to Yes. United Kingdom: Penguin Group.

Geldermann, J. \& Schobel, A. (2011). On the Similarities of Some Multi-Criteria Decision Analysis Methods. Journal of Multi-Criteria Decision Analysis, 18, 219-230.

Goyal, V. \& Saxena, A. S. (2002). Von Neumann And Morgenstern Utility Function. Delhi: Department of Computer Science and Engineering - Indian Institute of Technology Delhi.

Gul, F. (1991). A Theory of Disappointment Aversion. Econometrica, 59, 667-686.

Hershey, J. C., Kunreuther, H. C. \& Schoemaker, P. (1982). Sources of Bias in Assessment Procedures for Utility Functions. Management Science, 28(8), 936-954.

Hicks, J. R. \& Allen, R. (1934). A Reconsideration of the Theory of Value, Parts I and II. Economica, 1 (February, May): 52-76 and 196-219.

Kahneman, D. \& Tversky, A. (1979). Prospect Theory: An Analysis of Decision under Risk. Econometrica, 47(2), 263-291.

Kahneman, D., Wakker, P. P. \& Sarin, R. (1997). Back to Bentham? Explorations of Experienced Utility. Quarterly Journal of Economics, 112(2), 375-405.

Karmarkar, U. S. (1974). The Effect of Probabilities on the Subjective Evaluation of Lotteries. Cambridge, Massachusetts: Massachusetts Institute of Technology.

Kontek, K. (2010). Decision Utility Theory: Back to von Neumann, Morgenstern, and Markowitz. MPRA: Munich Personal RePEc Archive, 26.

Loomes, G. \& Sugden, R. (1987). Some Implications of a More General Form of Regret Theory. J. Econ. Theory, 41(2), 270-87.

Market Business News. (2019). What Is Utility? Definition And Meaning. Retrieved from Market Business News: https://marketbusinessnews.com/financial-glossary/utility-definition-meaning/

Markowitz, H. (1952). The Utility of Wealth. Journal of Political Economy, 60, 151-158.

McCord, M. \& de Neufville, R. (1983). Empirical Demonstration that Expected Utility Decision Analysis is Not Operational. Cambridge, USA: Massachusetts Institute of Technology.

McDermott, R. (1998). Risk-Taking in International Politics. USA: The University of Michigan Press.

Moscati, I. (2018). Measuring Utility: From the Marginal Revolution to Behavioral Economics. Oxford, UK: Oxford Scholarship Online.

Mosteller, F. \& Nogee, P. (1951). An Experimental Measurement of Utility. The Journal of Political Economy, 59(5), 371-404.

Pareto, V. (1892-1893). Considerazioni sui principii fondamentali dell'economia politica pura (Considerations on the Fundamental Principles of Pure Political Economy), Parts I-V. Giornale degli Economisti, (March, 1892): 389-420; (June, 1892): 485-512; (August, 1892): 119-157; (January, 1893): 1-37; (October, 1893): 279-321.

Quiggin, J. (1981). Risk perception and risk aversion among Australian farmers. Australian Journal of Agricultural Resource Economics, vol. 25, 160-169.

Quiggin, J. (1982). A Theory of Anticipated Utility. Journal of Economic Behavior and Organization, 3, 323343.

Roy, B. \& Bouyssou, D. (1993). Aide Multicritère á la Décision. Economica: Paris.

Schmeidler, D. (1989). Subjective Probability and Expected Utility without Additivity. Econometrica, 57, 571587.

Shaheen, F., Wooldridge, M. \& Jennings, N. R. (2009). An Analysis of Feasible Solutions for Multi-Issue Negotiation Involving Nonlinear Utility Functions. 8th International Conference on Autonomous Agents and Multiagent Systems (pp. pp. 1041-1048). Budapest, Hungary: AAMAS.

Simon, H. A. (1982). Models of Bounded Rationality. Volume 1: Economic Analysis and Public Policy. Volume 2: Behavioural Economics and Business Organization. MIT Press, 478-505.

Starmer, C. (2000). Developments in Non-Expected Utility Theory: The Hunt for a Descriptive Theory of Choice under Risk. Journal of Economic Literature, 38, 332-382.

Suppes, P. \& Walsh, K. (1957). A Non-linear Model for the Experimental Measurement of Utility. Stanford, California: Applied Mathematics and Statistics Laboratory.

Surbhi, S. (2016, 5 30). Difference Between Cardinal and Ordinal Utility. Retrieved from Key Differences: https://keydifferences.com/difference-between-cardinal-and-ordinal-utility.html 
Tversky, A. \& Kahneman, D. (1992). Advances in Prospect Theory: Cumulative Representation of Uncertainty. Journal of Risk and Uncertainty, 5, 297-323.

Viscusi, K. (1989). Prospective Reference Theory: Toward an Explanation of the Paradoxes. Journal of Risk and Uncertainty, 2, 235-264.

Voigt, A. (1893). Zahl und Mass in der Ökonomik. Eine kritische Untersuchung der mathematischen Methode und der mathematischen Preistheorie - Number and Measure in Economics. A Critical Study of Mathematical Method and Mathematical Price Theory. Zeitschrift für die gesamte Staatswissenschaft - Journal for the Entire Political Science, 49(4), 577-609.

von Neumann, J. \& Morgenstern, O. (1953). Theory of Games and Economic Behavior (Third ed.). Princeton, NJ: Princeton University Press.

von Neumann, J. \& Morgenstern, O. (1944). Theory of Games and Economic Behavior. US: Princeton University Press.

von Restorff, H. (1933). Uber die Wirkung von Bereichsbildungen im Spurenfeld [The effects of field formation in the trace field]. Psychologische Forschung, 18, 299-342.

Wall Street Mojo. (2019). Economic Utility. Retrieved from Wall Street Mojo: https://www.wallstreetmojo.com/economic-utility/

Wilkes, J. (2008). Utility Functions, Prices, and Negotiation. California, USA: John Wiley \& Sons Inc, HP Development Company.

Yaari, M. (1987). The Dual Theory of Choice under Risk. Econometrica, 55, 95-115.

Zartman, I. W. (1988). Common Elements in the Analysis of the Negotiation Process. Negotiation Journal, 4:31-43. 